\title{
Combinatorial immune and stress response, cytoskeleton and signal transduction effects of graphene and triphenyl phosphate (TPP) in mussel Mytilus galloprovincialis
}

\author{
Xiangjing Meng ${ }^{\mathrm{a}, \mathrm{c}}$, Fei Li ${ }^{\mathrm{a}, *}$, Xiaoqing Wang ${ }^{\mathrm{a}, \mathrm{c}}$, Jialin $\mathrm{Liu}^{\mathrm{a}}$, Chenglong $\mathrm{Ji}^{\mathrm{a}, \mathrm{b}}$, Huifeng $\mathrm{Wu}^{\mathrm{a}, \mathrm{b}, *}$ \\ ${ }^{a}$ CAS Key Laboratory of Coastal Environmental Processes and Ecological Remediation, Yantai Institute of Coastal Zone Research (YIC), Chinese Academy of Sciences \\ (CAS), Shandong Key Laboratory of Coastal Environmental Processes, YICCAS, Yantai 264003, PR China \\ ${ }^{\mathrm{b}}$ Laboratory for Marine Fisheries Science and Food Production Processes, Qingdao National Laboratory for Marine Science and Technology, Qingdao 266237, PR China \\ ${ }^{\mathrm{c}}$ University of Chinese Academy of Sciences, Beijing 100049, PR China
}

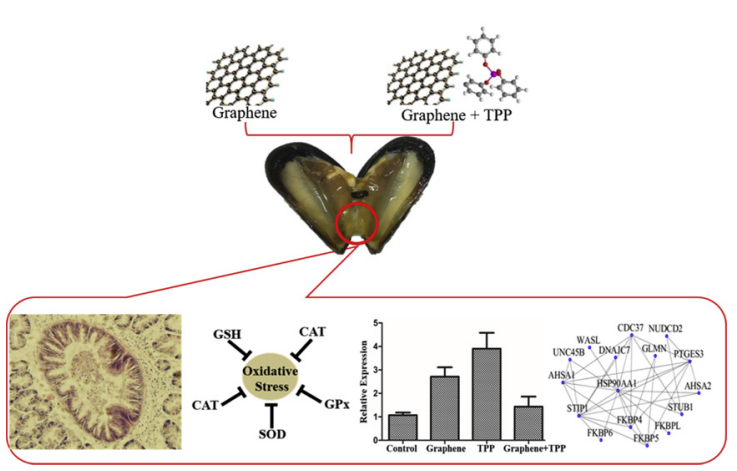

A R T I C L E I N F O

\section{Keywords:}

Joint effects

Graphene

Triphenyl phosphate (TPP)

Toxicity

Mussel

\begin{abstract}
A B S T R A C T
Owing to its unique surface properties, graphene can absorb environmental pollutants, thereby affecting their environmental behavior. Triphenyl phosphate (TPP) is a highly produced flame retardant. However, the toxicities of graphene and its combinations with contaminants remain largely unexplored. In this work, we investigated the toxicological effects of graphene and TPP to mussel Mytilus galloprovincialis. Results indicated that graphene could damage the digestive gland tissues, but no significant changes were found in the
\end{abstract}

\footnotetext{
Abbreviations: AFM, atomic force microscopy; AHSA1, activator of $90 \mathrm{kDa}$ heat shock protein ATPase homolog 1; AHSA2, activator of $90 \mathrm{kDa}$ heat shock protein

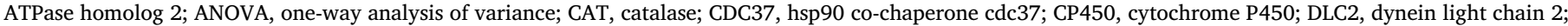

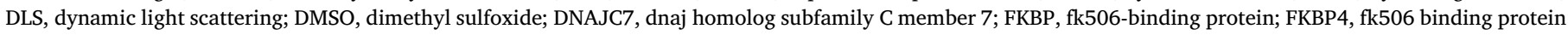

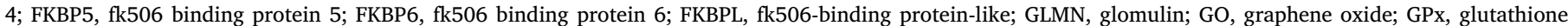

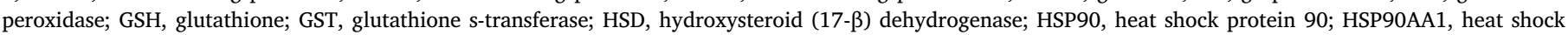

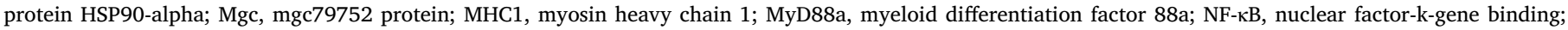

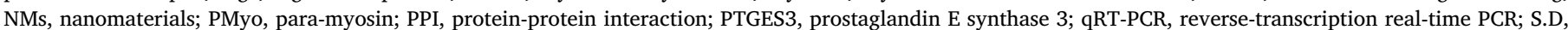

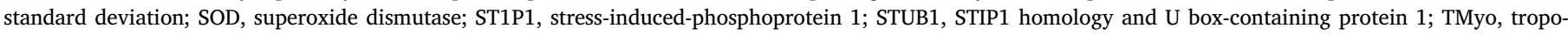

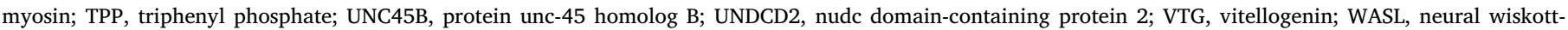
aldrich syndrome protein; $\beta$-actin, beta-actin

* Corresponding authors at: CAS Key Laboratory of Coastal Environmental Processes and Ecological Remediation, Yantai Institute of Coastal Zone Research (YIC), Chinese Academy of Sciences (CAS), Shandong Key Laboratory of Coastal Environmental Processes, YICCAS, Yantai 264003, PR China.

E-mail addresses: fli@yic.ac.cn (F. Li), hfwu@yic.ac.cn (H. Wu).
} 
graphene + TPP co-exposure group. There was a significant decrease in the content of GSH and the activities of GST and CAT in the co-exposure group compared to that in graphene-exposed group. It seemed that the adsorption of TPP on graphene could inhibit the surface activity of graphene and thus reduced its tissue damage and oxidative stress in mussels. Expression levels of stress response (MyD88a), cytoskeleton (MHC1, PMyo and TMYo) and reproductive ( $C P 450$ and $H S D$ ) genes were up-regulated in the graphene-exposed group, but significantly down-regulated after combined exposure of graphene and TPP. Furthermore, PPI analysis proved that the interactions of HSP9OAA1 with $U N C 45 B$ and $F K B P 4 / 5 / 6 / L$ contributed to the toxicity caused by the combined exposure. Because of the potential toxicity of graphene and TPP, government administrators should consider its risks prior to the widespread environmental exposure.

\section{Introduction}

Coastal and estuarine ecosystems have been heavily influenced by anthropogenic activities through pollution and habitat loss throughout the world [1]. In recent years, the production of nanomaterials (NMs) has been increased and the global production of NMs will be up to 58, $000 \mathrm{t}$ by 2020 [2]. Graphene is an emergent engineered nanomaterial. Due to its special electrical, optical, mechanical and chemical properties, graphene and its derivatives have been widely used in many fields [3]. Due to the limitations of the detection method, there are few reports on the environmental concentration of graphene, but it is expected that large quantities of graphene-based wastes will end up in the environment, representing a risk for the marine environment [4,5]. Thus, it becomes extremely important to investigate the potential toxicity of graphene and its derivatives on marine organisms in order to provide relevant data for the ecological risk assessment of graphene.

Previous work revealed that graphene nanotoxicity mainly focused on influencing cell growth and inducing oxidative stress [6]. The toxic effects of graphene and its derivatives were related to the dose and species sensitivity [7], which had been studied in various organisms such as algae, invertebrates and vertebrates (Table 1). Alga can be used as appropriate models to examine the toxicity of graphene and graphene oxide (GO). GO at $0 \sim 10 \mathrm{mg} / \mathrm{L}$ intensively entrapped singlecelled Chlorella vulgaris and reduced the cell permeability [8]. For the invertebrate, GO increased ROS production in exposed mussel M. galloprovincialis hemocytes at a wide range of concentrations (up to $25 \mathrm{mg}$ / L) [9]. Studies showed that graphene could induce oxidative stress in brine shrimp (Artemia salina) at concentrations ranging from 0.5 to $1.0 \mathrm{mg} / \mathrm{L}$ [10]. The embryonic development of zebrafish (Danio rerio) is a common testing model for the developmental toxicity of chemicals. GO affected the development of heart and skeleton to cause deformity in zebrafish at concentrations ranging from 0.001 to100 mg/L [11,12]. Researches on the model species, pseudomonas aeruginosa (Microcystis aeruginosa) also found that graphene could affect the enzyme activities associated with oxidative stress [13].

Once entering the environment, graphene can easily interact with other pollutants through hydrophobic, $\pi-\pi$ stacking and hydrogen bonding interactions (such as heavy metals, organic pollutants, etc.), thereby affecting their environmental distributions and interactions with organisms [14]. Liu et al. showed that low levels of graphene
$(0.01 \mu \mathrm{g} / \mathrm{mL})$ and $\mathrm{GO}(5 \mu \mathrm{g} / \mathrm{mL})$ could increase the cell toxicity of arsenic [15]. In addition, Hu et al. found that GO and copper had significant antagonism against $S$. obliquus, and GO could reduce the ecotoxicity of copper even at environmentally relevant concentrations ( 1 mg/L) [5].

Triphenyl phosphate (TPP) was a high-production flame retardant that had been detected in many environmental media and biota $[16,17]$. Currently, there are no threshold limits for graphene and TPP issued by regulatory authority. The concentrations of TPP ranged from 7 to $209 \mathrm{pg} / \mathrm{g}$ dry weight (dw), with the geometric mean (GM) of $40 \mathrm{pg}$ / $\mathrm{g} \mathrm{dw}$ in the surface sediment from the Bohai Sea and Yellow Sea [18]. Studies showed that TPP could induce developmental toxicity, neurotoxicity and endocrine disruption at $0.01 \sim 100 \mathrm{mg} / \mathrm{L}$ [19]. Acute toxicity data for TPP were also available for algae (median effective concentration $\left[E C_{50}\right], 0.26-2.0 \mathrm{mg} / \mathrm{L}$ ) [20]. Moreover, TPP contains three benzene rings, and easily lead to the adsorption by graphene. Graphene has high hydrophobicity and durability, which may increase the accumulation of TPP and transmit it to humans through the food chain. Our previous studies showed that combined graphene + TPP exposure could aggravate the damage of simulated bio-membrane induced by single graphene or TPP exposure [21]. Thus, it also becomes important to elucidate the joint effects of graphene + TPP exposure.

Mussel M. galloprovincialis is often used as a preferable bioindicator for the marine environmental pollutants and investigated as an experimental species in ecotoxicology [22,23]. As a filter-feeder, M. galloprovincialis has the ability to accumulate and tolerate huge amounts of pollutants. In this study, the effects of graphene, TPP and graphene + TPP on M. galloprovincialis were investigated by tissue sections, antioxidant status and reverse-transcription real-time PCR (qRTPCR). The histopathological changes and antioxidant status of digestive gland tissues were used to evaluate the responses of $M$. galloprovincialis exposed to graphene and TPP. The expressions of certain functional genes including immune stress response, cytoskeleton, intracellular signal transduction and reproductive were determined after the graphene, TPP and their combined exposures. In addition, the network of protein interactions induced by the combined graphene + TPP exposure was clarified.

Table 1

The biological toxicities of graphene and its derivatives.

\begin{tabular}{|c|c|c|c|c|c|}
\hline NMs & Species & Time & Concentration & Toxicity & Ref \\
\hline Graphene & Brine shrimp (Artemia salina) & $48 \mathrm{~h}$ & $0.5-1.0 \mathrm{mg} / \mathrm{L}$ & graphene could induce oxidative stress & [10] \\
\hline GO & Zebrafish embryos & $96 \mathrm{~h}$ & $1-100 \mu \mathrm{g} / \mathrm{L}$ & GO affected the development of heart and skeletal; & [11] \\
\hline GO & Zebrafish embryos & $96 \mathrm{~h}$ & $1-100 \mathrm{mg} / \mathrm{L}$ & GO caused zebrafish deformity, affected the heart rate; & [12] \\
\hline
\end{tabular}

Abbreviations: GO, graphene oxide; NMs, nanomaterials. 


\section{Materials and methods}

\subsection{Test compounds and graphene characterization}

Graphene $(1.0 \mathrm{mg} / \mathrm{mL})$ was purchased from Sigma-Aldrich (Shanghai, China), and TPP (purity $>98 \%$ ) was obtained from Dr. Ehrenstorfer Co., Ltd. The shape and size of graphene were characterized by atomic force microscopy (AFM, Veeco Multimode $8+$ bioscope catalyst, USA). The size and charge distribution were analyzed at $0 \mathrm{~h}$, $6 \mathrm{~h}, 12 \mathrm{~h}$ and $24 \mathrm{~h}$, using dynamic light scattering (DLS) and the zeta potentials analyzer (Malvern, Zetasizer Nano Sizer, Nano-2S90, U.K.), respectively. Raman spectra were confirmed by a DXR Raman spectrophotometer (Thermal Fisher, USA) with a $633 \mathrm{~nm}$ laser source. Graphene was dispersed in the natural salt water (32\%o salinity), at room temperature $\left(18 \pm 1{ }^{\circ} \mathrm{C}\right)$ prior to the above characterization. To reduce the aggregation of graphene during the preparation, the graphene suspension was sonicated at $100 \mathrm{~W}$ (Shumei, KQ-5200DE, China) for $15 \mathrm{~min}$ [11].

\subsection{Animals and treatments}

Mussels (5.0 $\pm 1.0 \mathrm{~cm}$ in length) were obtained from the Zhifu Island in Yantai (Shandong, China). Experimental animals were acclimatized for 7 days under laboratory conditions with aerated seawater (500 mesh sieved), at $18 \pm 1{ }^{\circ} \mathrm{C}$ and $32 \%$ salinity. Hu et al. reported that the environmentally relevant concentration of graphene oxide (GO) was $1 \mathrm{mg} / \mathrm{L}$ [5]. For the TPP, the $E C_{50}$ values of the marine invertebrate were $0.26 \sim 2.0 \mathrm{mg} / \mathrm{L}$ [9]. Based on these, the effects of graphene and TPP at $0.5 \mathrm{mg} / \mathrm{L}$ to mussel Mytilus galloprovincialis were investigated in the present work.

For the experiments, twenty animals per replicate were assigned to $10 \mathrm{~L}$ glass-beakers and exposed to graphene, TPP and graphene + TPP for 7 days for each of the following treatments: Control (C), $0.5 \mathrm{mg} / \mathrm{L}$ graphene (G), $0.5 \mathrm{mg} / \mathrm{L}$ TPP (T), combined $0.5 \mathrm{mg} / \mathrm{L}$ graphene and $0.5 \mathrm{mg} / \mathrm{L}$ TPP exposure $(\mathrm{G}+\mathrm{T})$. Seawater was changed daily, and both graphene and TPP were re-dosed at a nominal concentration of $0.5 \mathrm{mg}$ / L. During the acclimation and entire exposure periods, mussels were under a photo-period of $12 \mathrm{~h}$ light and $12 \mathrm{~h}$ dark, and fed with Chlorella vulgaris daily. No mortality of mussels was observed during the experiments. At the end of exposure period, the digestive gland was randomly dissected from 12 mussels for each treatment and used for the further study. The methods for histology and antioxidant status analysis of digestive gland tissues exposed to graphene and TPP could be found in the Supporting Information.

\subsection{Concentrations of TPP in biota}

Following the previous studies [18], the concentrations of TPP in biota were detected by gas chromatograph Agilent 7890A GC coupled with a triple quadrupole mass spectrometer Agilent 7010 MS (GC-MS/ MS) equipped with a programmed temperature vaporizer (PTV) injector (Agilent Technologies, USA). The details were shown in the Supporting Information.

\subsection{RNA extraction and $q R T-P C R$ analysis}

In order to investigate the possible mechanisms of toxicity caused by graphene and TPP, several gene expression levels were quantified by qRT-PCR technique. The target genes were involved in immune stress response (FKBP, HSP90, NF- $K B$ and MyD88a), cytoskeleton (Matrilin, DLC2, MHC1, Pmyo and TMyo), intracellular signal transduction (Cublin and $M g c$ ) and reproduction (CP450, VTG and HSD). Gene-specific primers in this study were shown in Table 2. The methods for Total RNAs extraction and qRT-PCR analysis could be found in the Supporting Information. The interacting partners of proteins for all the selected functional genes were identified using STRING 11.0 database (https:// string-db.org). The protein-protein interaction (PPI) networks were constructed and visualized using Cytoscape 3.7.1 (http://www. cytoscape.org/download.php).

Table 2

The primers for qRT-PCR in this study.

\begin{tabular}{|c|c|c|c|c|c|}
\hline Gene name & Full name & Correlation function & GenBank accession No. & Primer name & Primer sequence $\left(5^{\prime}-3^{\prime}\right)$ \\
\hline \multirow[t]{2}{*}{$\beta$-actin } & beta-actin & endogenous control & GT157817 & $\beta$-actin-F & GCTATCCAGGCCGTACTCT \\
\hline & & & & $\beta$-actin-R & GCGGTGGTTGTGAATGAG \\
\hline \multirow[t]{2}{*}{ FKBP } & Fk506-binding protein & immune stress response & AJ625569 & FKBP-F & GATTGCCGAGTTACTGCTGA \\
\hline & & & & FKBP-R & TACAGTTTTCGTACTGAACGGAA \\
\hline \multirow[t]{2}{*}{ HSP9O } & Heat shock protein 90 & immune stress response & AJ625915 & HSP90-F & AAGCTGATCTGGTCAATAACCTGG \\
\hline & & & & HSP90-R & AACCTACACCAAACTGTCCAATCA \\
\hline \multirow[t]{2}{*}{$N F-\kappa B$} & NF- $\mathrm{KB}$ transcription factor Rel & immune stress response & HQ127223.2 & NF-кB-F & ATACCTCTTCCGTCCGCACTT \\
\hline & & & & NF-kB-R & AAGAAGCTGCCGCTAAATCGA \\
\hline \multirow[t]{2}{*}{ MyD88a } & Myeloid differentiation factor $88 \mathrm{a}$ & immune stress response & JX112712.1 & MyD88a-F & CGCTGGCGATGAGAAATATGTAG \\
\hline & & & & MyD88a-R & TTTGCACCTGGTGATAAGGACTG \\
\hline \multirow[t]{2}{*}{ Matrilin } & Matrilin & extracellular matrix proteins & AJ625256 & Matrilin-F & AACATATACAGGCAAAGCACTACA \\
\hline & & & & Matrilin-R & TCACCATCCGTAATGATAATTGCA \\
\hline \multirow[t]{2}{*}{$D L C 2$} & Dynein light chain 2 & motor protein light chain & AJ516886 & DLC2-F & TCAGTGATGATCCTAGATTAGGCA \\
\hline & & & & DLC2-R & CGTTCCTCTCTTTCCATCTGTAAC \\
\hline \multirow[t]{2}{*}{ MHC1 } & Myosin heavy chain 1 & myosin heavy chain & AJ249992.1 & MHC1-F & GAGGGAATCCAGTGGGAGTTTAT \\
\hline & & & & MHC1-R & TGGTTTGGTGAAGTTGGGTGAT \\
\hline \multirow[t]{2}{*}{ PMyo } & Para-myosin & vice myosin & AB016070.1 & PMyo-F & ATAAATACCGCAAAGCCCAATC \\
\hline & & & & PMyo-R & TTACTTCCCGTGAGACAGACATAGA \\
\hline \multirow[t]{2}{*}{ TMyo } & Tropo-myosin & tropomyosin & AB000907.1 & TМуо-F & TGAAGAGCAGCTCACAGTTGTTG \\
\hline & & & & TMyo-R & TTCATCTTCCAATCGGTCTACTTC \\
\hline \multirow[t]{2}{*}{ Cublin } & cubilin & intracellular signal transduction & AJ626333 & Cublin-F & TGTCACTACTAAAACGAGCAGAGCG \\
\hline & & & & Cublin-R & CTTTGGTTCCATCACAGGTTTCAC \\
\hline \multirow[t]{2}{*}{$M g c$} & mgc79752 protein & intracellular signal transduction & AJ624360 & Mgc-F & TTCTTGGCACAACTTTGTCTGC \\
\hline & & & & Mgc-R & CCCATGAGGACCTAGTTCTTTGG \\
\hline \multirow[t]{2}{*}{ CP450 } & cytochrome P450 & sex hormone synthesis & FL499705.1 & CP450-F & GATTGAATATGCCTTACTGTGACG \\
\hline & & & & CP450-R & CTGGATCTGGATAAATGTTCTCATC \\
\hline \multirow[t]{2}{*}{$V T G$} & vitellogenin & vitellogenin & AJ625462.1 & VTG-F & GAGCCAAGTGTTGTTGGTGAT \\
\hline & & & & VTG-R & CTGGGATGCTGATTTGAATG \\
\hline \multirow[t]{2}{*}{$H S D$} & hydroxysteroid (17- $\beta$ ) dehydrogenase & hydroxyl steroid dehydrogenase & FL499705.1 & HSD-F & GATAAGATTGGCAGTTGGACTGAT \\
\hline & & & & HSD-R & ATAGTACAACATCTGATGCCCTGA \\
\hline
\end{tabular}




\subsection{Statistical analysis}

All the data were reported as mean \pm standard deviation (S.D). Statistical differences in biological parameters between control and treatments were evaluated by one-way analysis of variance (ANOVA) using SPSS 22.0 software. Before ANOVA, the normality and homogeneity of variances were verified. Differences were considered statistically significant at a value of $P<0.05$.

\section{Results and discussion}

\subsection{Histological observation of digestive gland in mussels $M$. galloprovincialis exposed to graphene and TPP}

As shown in Fig. 1, there was a minor degree of tissue loss in graphene-exposed mussels compared with control group. For the TPP-exposed group, no obvious damage was observed. The effect of graphene was related to its inherent surface characteristics [25]. As shown in the AFM pictures (Fig. S1A), the horizontal size of graphene layers was large and the edge was very sharp. After entering the digestive tract, graphene could cause damage to the digestive tract [26]. However, there was no obvious tissue damage in the mussels from graphene + TPP co-exposure group. In our study, the average TPP concentration in the co-exposed group (770.77 $\pm 425.69 \mu \mathrm{g} / \mathrm{g}$ fat weight) was higher than that in the TPP-exposed group $(404.57 \pm 258.22 \mu \mathrm{g} / \mathrm{g}$ fat weight) (about 1.9 times), presenting enhanced bioaccumulation of TPP. This might be explained that the adsorption of TPP reduced the surface sharpness of graphene. Hence, there was no significant change of the tissue damage in the graphene + TPP exposure group.

\subsection{Antioxidant status of digestive gland tissue exposed to graphene and} TPP

The antioxidant enzyme activities and the antioxidant contents can reflect the oxidation state of the organism [27]. As shown in Table 3, after the exposure of $0.5 \mathrm{mg} / \mathrm{L}$ graphene, the content of GSH and the
Table 3

Antioxidant enzyme activities and GSH content in digestive gland tissues of M. galloprovincialis after a $7 \mathrm{~d}$ exposure of graphene and TPP*.

\begin{tabular}{lllll}
\hline Groups & Control & Graphene & TPP & Graphene + TPP \\
\hline GSH & $3.09 \pm 0.27$ & $4.15 \pm 0.29^{\mathrm{a}}$ & $3.64 \pm 0.33$ & $2.26 \pm 0.29^{\mathrm{b}, \mathrm{c}}$ \\
GPx & $65.48 \pm 3.37$ & $81.44 \pm 3.45^{\mathrm{a}}$ & $45.56 \pm 1.52^{\mathrm{a}}$ & $70.00 \pm 1.41^{\mathrm{b}, \mathrm{c}}$ \\
GST & $40.88 \pm 1.40$ & $40.20 \pm 2.99$ & $49.92 \pm 1.75^{\mathrm{a}}$ & $33.07 \pm 1.08^{\mathrm{a}, \mathrm{c}}$ \\
SOD & $28.14 \pm 0.71$ & $31.30 \pm 1.38^{\mathrm{a}}$ & $26.20 \pm 1.19$ & $31.26 \pm 1.33^{\mathrm{a}}$ \\
CAT & $35.53 \pm 2.86$ & $43.24 \pm 5.79^{\mathrm{a}}$ & $39.98 \pm 3.00^{\mathrm{a}}$ & $37.73 \pm 1.75^{\mathrm{a}, \mathrm{b}}$ \\
\hline
\end{tabular}

* The data are presented as the mean \pm S.D

a $P<0.05$, compared with the control group.

b $P<0.05$, compared with the graphene-exposed group.

c $P<0.05$, compared with the TPP-exposed group. GSH, glutathione; GPx, glutathione peroxidase; GST, glutathione s-transferase; SOD, superoxide dismutase; CAT, catalase.

activities of GPx, SOD and CAT in the digestive gland tissues were increased significantly $(P<0.05)$. In the TPP-exposed group, the activities of CAT and GST were increased remarkably $(P<0.05)$. Mittal et al. [28] reported that the content of GSH and the level of ROS in human lung cells were increased obviously after exposure to graphene. Graphene also could enhance the oxidative stress in Artemia salina, and influenced the activities of antioxidant enzymes (GST, CAT, GPx and SOD) and the content of MDA [29]. Moreover, Chen et al. found that TPP exposure affected the expressions of antioxidant enzymes and related genes (GPX, CAT and GST) [30]. Our findings were consistent with previous studies, indicating that both TPP and graphene could induce oxidative stress in mussels.

Interestingly, there was a significant decrease in the content of GSH and the activities of GST and CAT in the graphene + TPP co-exposure group $(P<0.05)$ compared to that in graphene-exposed group. It seemed that the level of oxidative stress in the combined exposure group was lower than that in the graphene-exposed group. As described above, graphene enhanced the accumulation of TPP in M. galloprovincialis, it was believed that the adsorption of TPP on graphene could
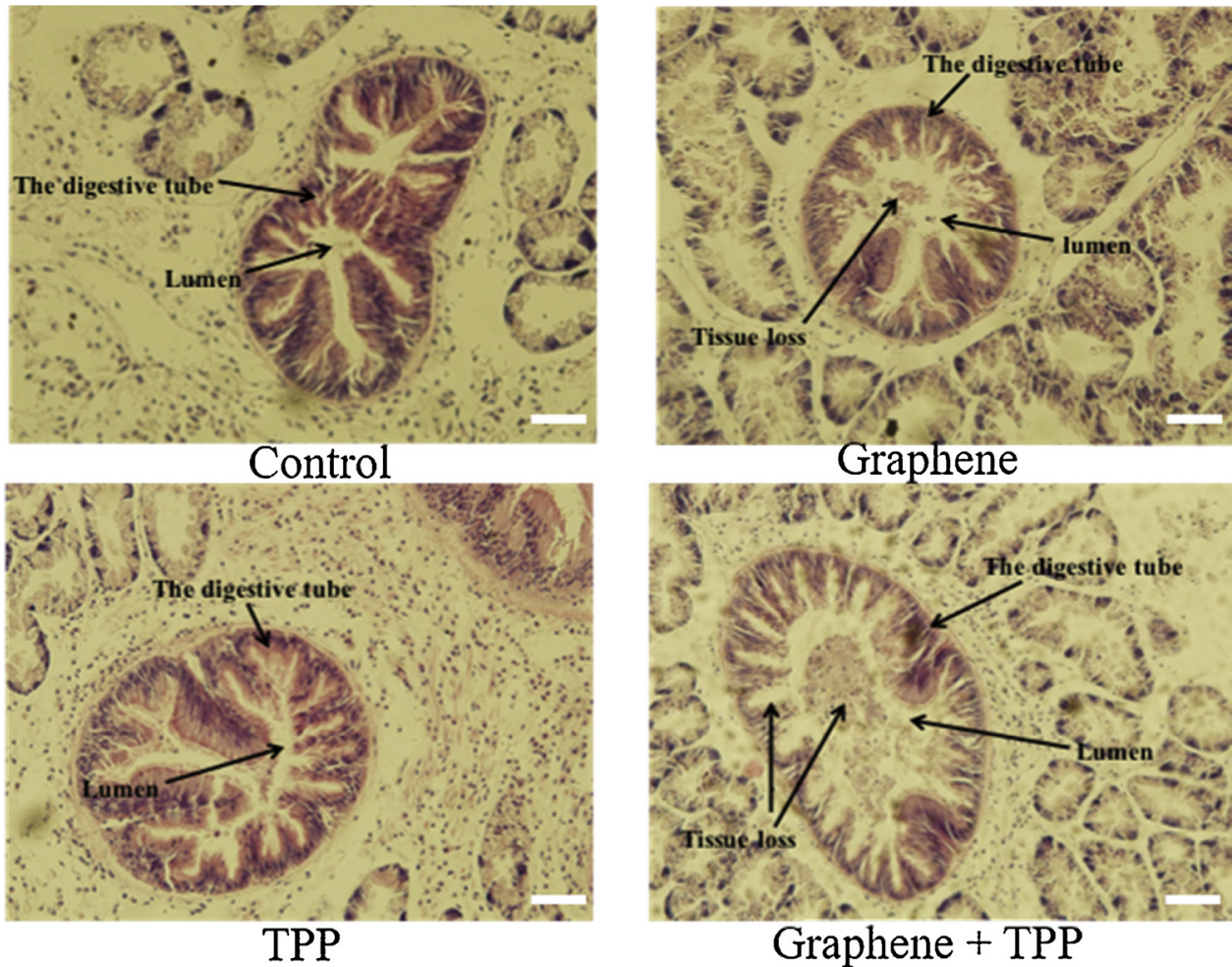

Fig. 1. The histopathology images of the digestive gland tissues after exposures to graphene, TPP and graphene + TPP $(\times 400)$, scale bar is $20 \mu \mathrm{m}$. 
inhibit the surface activity of graphene and thus reduce its toxicity.

Oxidative stress could cause tissue damage, cell membrane damage, mitochondrial dysfunction and other toxic effects [31]. To gain insights into the possible mechanisms of the combined effects of graphene + TPP in M. galloprovincialis, the expression levels of 14 genes involved in immune stress response, cytoskeleton, intracellular signal transduction and reproductive were determined as followed.

\subsection{Effect of graphene and TPP on immune stress reaction gene expressions} in the digestive gland tissue of mussels

The relative expressions of $H S P 90$ and FKBP genes were obviously up-regulated in the graphene-exposed group. In addition, $H S P 90, N F-\kappa B$ and $M y D 88 a$ genes were notably up-regulated in the TPP-exposed group (Fig. 2). Researches have demonstrated that GO could increase the oxidative stress parameters and the level of HSP7O in Acheta domesticus [32]. According to Zhi et al., C. elegans could regulate gene expression as a response to oxidative stress due to the existence of graphene [33]. The oxidative stress and endocrine related genes in mice were influenced remarkably by TPP exposure [30]. Our findings were consistent with these previous results. These gene expression profiles indicated that both graphene and TPP could induce obvious immune stress in the digestive gland tissues of mussels.

The MyD88a gene encodes myeloid differentiation factor 88a, and significantly affects the muscle Toll receptor 9 (TLR9) signaling pathway. As the key components in immune signaling of invertebrates, Toll-like receptors are expressed in M. galloprovincialis hemocytes and digestive gland [34]. As shown in Fig. 2, a more considerable downregulation in the level of MyD88a was observed in the graphene + TPP co-treatment group than that in graphene-exposed group. Liu et al. revealed that graphene could reduce the cell and genetic toxicity caused by PCB52, which was closely related to the induction of genuine autophagy [35]. Based on this finding, it was concluded that the combined graphene + TPP exposure could reduce the immune stress caused by graphene in tissues, which was consistent with the alteration of antioxidant enzyme activities.

\subsection{Effect of graphene and TPP on intracellular signal transduction and reproduction gene expressions in the digestive gland tissue of mussels}

Intracellular signal transduction plays an important role in the maintenance of cell normal biological function [36]. There was an increase in relative expressions of Cubilin and $M g c$ in mussel digestive gland tissues with exposure to $0.5 \mathrm{mg} / \mathrm{L}$ graphene and TPP, respectively (Fig. 3A). Cubilin is a receptor protein that on cell membrane encoded by Cubilin gene. As a receptor protein, Mgc 79752 protein plays an important role in signal transduction of cells [37]. It seemed that graphene and TPP could affect the intracellular signal transduction in the digestive gland tissues of mussels.

After graphene + TPP exposure, the relative expression of $M g c$ was significantly down-regulated in comparison with that in graphene-exposed group. However, the up-regulation of tubulin isoforms and Mgc protein were observed in mussels exposed to $\mathrm{n}-\mathrm{TiO}_{2}$ and the $\mathrm{n}-\mathrm{TiO}_{2} /$ TCDD mixture, respectively [37]. It might be explained that the two receptor proteins, Cubilin and $M g c$ were involved in different signal transduction pathways, thus resulting in the different levels of gene expression induced by exogenous pollutants. Therefore, the specific mechanism needs further explorations.

The relative expressions of CP450 and VTG genes in graphene-exposed group had no significant changes in comparison with the control group, while the expression of $H S D$ was evidently up-regulated (Fig. 3B). For the TPP-exposed group, the relative expressions of CP450, $V T G$ and HSD genes were significantly down-regulated. CP450 gene encodes cytochrome $\mathrm{P}-450$ protein participating in the foreign chemical hydrolysis, reduction and oxidation reaction, and also plays an important role in regulating the synthesis of sterols hormones in body (most sex hormones are sterols hormone) [38]. VTG gene encodes vitellogenin that is the precursor of yolk protein for almost oviparous animals [39]. Vitellogenin can provide amino acids, fat, carbohydrates, vitamins and other nutrients for the developing embryo [40]. 17 $\beta$-HSDs (HSD) mainly express in digestive gland and gonads of mussels and can regulate the activities of sex hormones [41].

Liu et al. [19,42] showed that TPP could affect the balance of sex hormone in Danio rerio, and then affect the reproductive capacity. TPP could also inhibit the expression of cytochrome P-450 26a1 (CYP26a1), and induce the reproductive toxicity in Danio rerio [43]. Chen et al. [31] found that TPP could evidently inhibit the expression of cytochrome P450 cholesterol side-chain lyase (CP450scc) and 17 $\alpha$-hydroxy steroid dehydrogenase (17 $\alpha$-HSDs) genes, showing obvious reproductive toxicity. These results showed that TPP could inhibit the expression of reproduction genes and thus influenced reproductive toxicity in mussels.

Graphene had a certain effect on reproductive related gene expression. Compared with the graphene-exposed group, significant decreases in the levels of $C P 450$ and HSD levels were observed in the graphene + TPP co-treatment group. After exposure with graphene + TPP, the expression levels of CP450 and HSD were not consistent with other functional genes, and the mechanism should be further studied.

\subsection{Effects of graphene and TPP on cytoskeleton gene expressions in the digestive gland tissue of mussels}

The relative expressions of Matrilin and MHC1 genes were significantly up-regulated in the mussel digestive gland tissue after exposure to $0.5 \mathrm{mg} / \mathrm{L}$ graphene and $0.5 \mathrm{mg} / \mathrm{L}$ TPP for 7 days, respectively (Fig. 4). It was reported that the bending stiffness of graphene was similar to the lipid bilayers of cells, which was beneficial to the close interactions between graphene and membrane proteins [44]. Smaller graphene with sharp edges could be engulfed by cells to interact and possibly to cut actin filaments leading to destruction of the cytoskeleton [45]. Tian et al. found that graphene nanosheets could change the secondary structures of actin monomers, and affected cell microfilament structure, thus affected the material migration and transportation in human A549 lung cancer cell [46]. The expression profiles of these

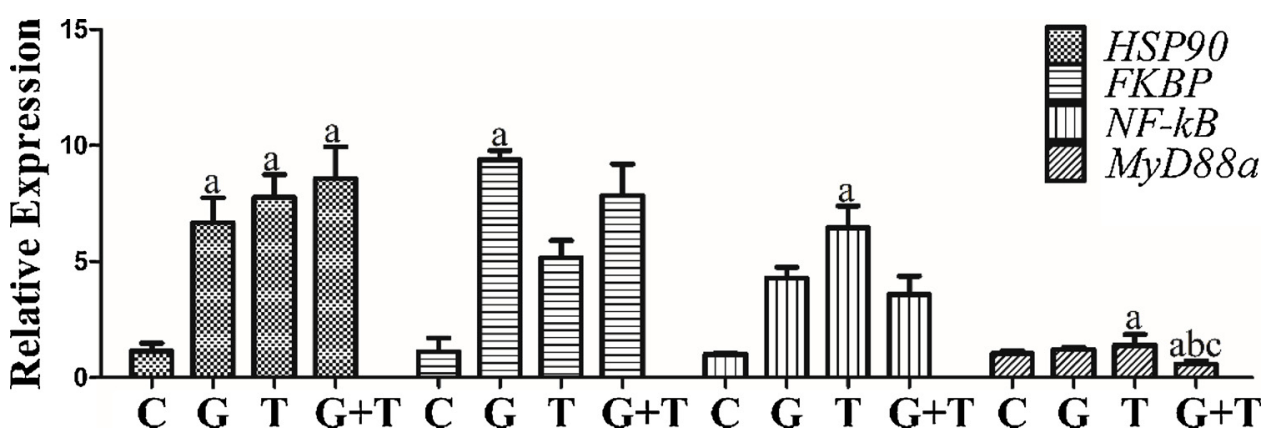

Fig. 2. Relative expressions of genes associated with immune response and stress response in the digestive gland tissues of $M$. galloprovincialis after a $7 \mathrm{~d}$ exposure. C: control group; G: graphene-exposed group; T: TPP-exposed group; $\mathrm{G}+\mathrm{T}$ : graphene + TPP-exposed group. ${ }^{\text {a }} P<0.05$, compared with the control group, ${ }^{\mathrm{b}}$ $P<0.05$, compared with the graphene-exposed group, ${ }^{\mathrm{c}} P<0.05$, compared with the TPP-exposed group. 


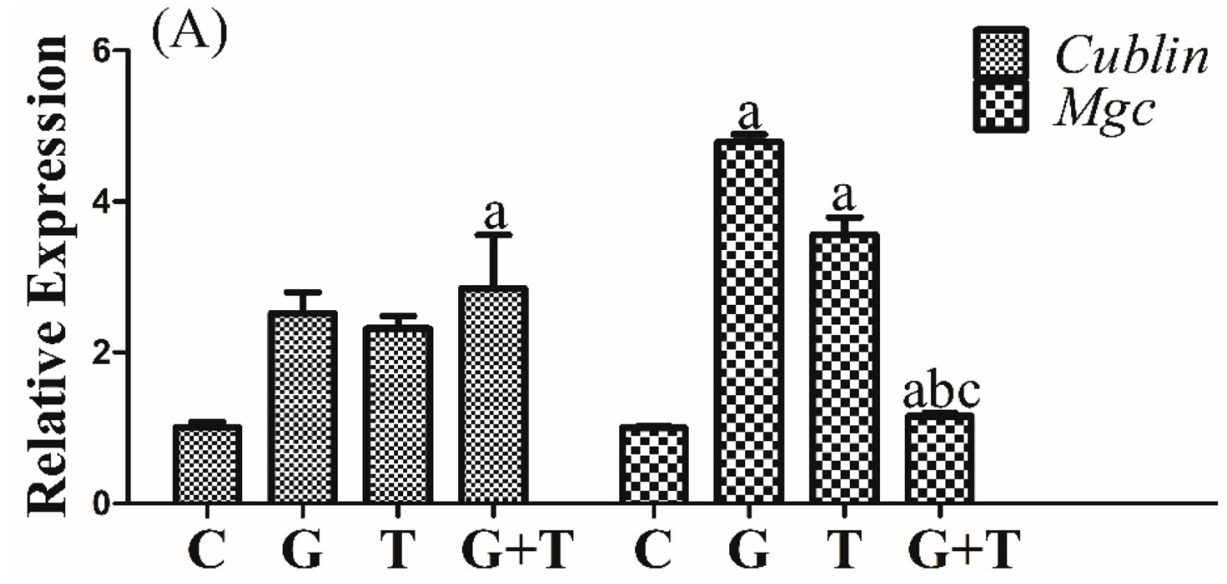

Fig. 3. Relative expressions of genes associated with intracellular signal transduction (A) and reproduction (B) in the digestive gland tissues of M. galloprovincialis after a $7 \mathrm{~d}$ exposure. C: control group; G: graphene-exposed group; T: TPP-exposed group; G + T: graphene + TPPexposed group. ${ }^{\mathrm{a}} P<0.05$, compared with the control group, ${ }^{\mathrm{b}} P<0.05$, compared with the graphene-exposed group, ${ }^{\mathrm{c}} P<0.05$, compared with the TPP-exposed group.

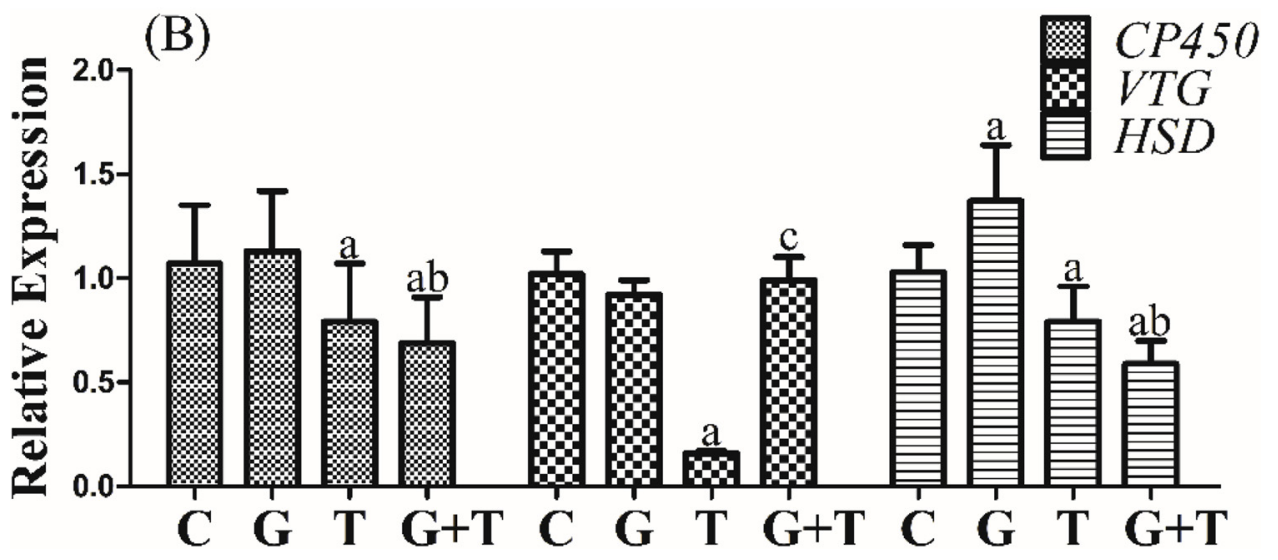

genes indicated that both graphene and TPP affected the internal and external cellular structures of cells as well as the transport of substances in cells.

Compared with the graphene-exposed group, the relative expressions of DLC2, MHC1 and PMyo genes were evidently down-regulated in mussel samples after combined graphene + TPP exposure, which suggested that combined exposure of graphene and TPP could reduce the effect induced by grapheme on the cell structure and material transport in mussel samples.

3.6. Construction of regulatory molecular pathways of graphene + TPP and M. galloprovincialis interaction

Systematic prediction of interaction network would help explore complex gene networking [47]. To elucidate the mechanism of action, online STRING 11.0 database was used to construct portable PPI networks based on the selected functional-related genes, and the interrelationship was visualized by Cytoscape 3.5.1. As shown in Fig. 5, these genes associated with stress response (HSP9OAA1, FKBPL, FKBP4 and FKBP5), cytoskeleton (UNC45B) and reproduction (FKBP6) interacted with each other.

The heat-shock proteins (HSP) are highly conserved family in all living organisms, and play an essential role in cell homeostasis [33]. In our study, the relative expression of HSP9O gene was obviously upregulated in the graphene + TPP co-exposure group (Fig. 2). FKBP4, FKBP5 and FKBPL proteins belong to immunophilins family and play roles in immune regulation. They are believed to be related with protein folding and transport, and participate in cellular stress responses [48]. The interactions between $F K B P 4 / 5 / L$ and $H S P 90$ promoted the formation of steroid receptor heterocomplex, which might protect mussels from oxidative damage leading to the considerable changes of antioxidant levels in mussel digestive gland tissues (Table 3).

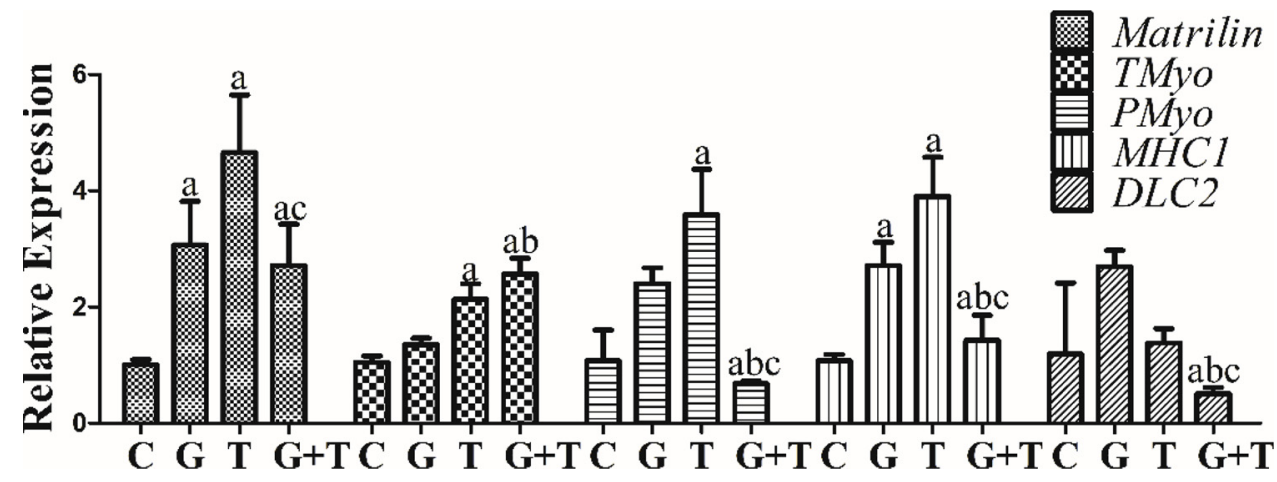

Fig. 4. Relative expressions of genes associated with cytoskeleton and cell movement in the digestive gland tissues of $M$. galloprovincialis after a $7 \mathrm{~d}$ exposure. C: control group; G: graphene-exposed group; T: TPP-exposed group; $\mathrm{G}+\mathrm{T}$ : graphene + TPP-exposed group. a $P<0.05$, compared with the control group, ${ }^{\mathrm{b}}$ $P<0.05$, compared with the graphene-exposed group, ${ }^{\mathrm{c}} P<0.05$, compared with the TPP-exposed group. 


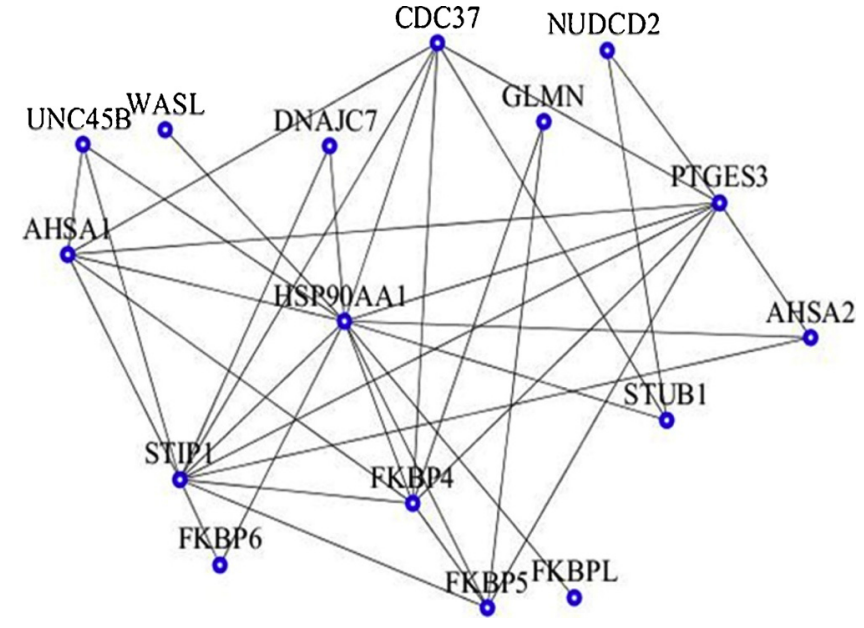

Fig. 5. Network analysis of combination graphene + TPP exposure for M. galloprovincialis. HSP90AA1, heat shock protein HSP90-alpha; FKBP4, FK506 binding protein 4; FKBP5, FK506 binding protein 5 ; FKBP6, FK506 binding protein 6; FKBPL, FK506-binding protein-like; ST1P1, stress-induced-phosphoprotein 1; STUB1, STIP1 homology and U box-containing protein 1; AHSA1, activator of $90 \mathrm{kDa}$ heat shock protein ATPase homolog 1; AHSA2, activator of $90 \mathrm{kDa}$ heat shock protein ATPase homolog 2; PTGES3, prostaglandin E synthase 3; UNDCD2, nudc domain-containing protein 2; CDC37, hsp90 co-chaperone cdc37; DNAJC7, dnaj homolog subfamily C member 7; WASL, neural wiskott-aldrich syndrome protein; UNC45B, protein unc-45 homolog B; GLMN, glomulin.

UNC45B (Unc-45 homolog B) is a co-chaperone of HSP90, as well as requiring for proper folding of myosin motor domain, playing an important role in the development and formation of muscle fibers [49]. In the network (Fig. 5), the effect on cytoskeleton induced by graphene + TPP was mediated by UNC45B. Besides, results of the present study demonstrated that graphene + TPP co-exposure showed an obvious reproductive toxicity (Fig. 3). Sisakhtnezhad et al. indicated that FkBP6 was associated with the self-renewal and maintenance of spermatogonial stem cells (SSCs), which played a key role in the process of spermatogenesis [50]. Therefore, graphene + TPP could induce reproductive toxicity by affecting the expression of FKBP6. Zhang et al. also found the developmental toxicity of GO at trace concentrations $(1 \sim 100 \mu \mathrm{g} / \mathrm{L})$ [11].

The PPI results of graphene + TPP co-exposure showed that the interactions of $F K B P 4 / 5 / L$ with $H S P 90$ could effectively influence the antioxidant levels in mussel digestive gland tissues. The effects of combined exposure on cytoskeleton and reproduction might be related to the interaction of HSP9OAA1 with UNC45B and FKBP6.

As typical flame retardants, tetrabromobisphenol A (TBBPA) and 2,2',4,4'-tetrabromodiphenyl ether (BDE-47) were traditional chemical pollutants that were widely distributed in the marine environment. At a wide range of concentrations ( $\mathrm{ng} / \mathrm{L} \sim \mathrm{mg} / \mathrm{L}$ ), they could induce various toxicities, such as hepatotoxicity, nephrotoxicity, immunotoxicity, genotoxicity and endocrine disrupting effects in animals [51,52]. In the present study, graphene and TPP at the low concentration $(0.5 \mathrm{mg} / \mathrm{L})$ could induce immune and oxidative stress. We also found that combined exposure of graphene and TPP could increase the potential reproductive toxicity to mussels. However, there are no threshold limits for graphene and TPP issued by government administrators. Therefore, the potential environmental risks should be considered before their widespread exposure.

\section{Conclusions}

Compared to the graphene exposure, graphene + TPP co-exposure could reduce the tissue damage and antioxidant status in the digestive gland tissues. Moreover, the genes in terms of immune and stress response (MyD88a), cytoskeleton (MHC1, PMyo and TMyo) and reproductive ( $C P 450$ and $H S D$ ) were significantly down-regulated in the combined graphene and TPP-treated group, comparing with those in the graphene-exposed group. Our research indicated that combined exposure of graphene and TPP could affect cytoskeleton and stress response. The reproductive toxicity caused by graphene + TPP might be related to FKBP6, and the mechanism should be further studied. The study could provide valuable information for understanding possible toxicity mechanisms of graphene and its combination with other contaminants to marine organisms.

\section{Acknowledgments}

This research was supported by the National Natural Science Foundation of China (41530642, 21677173) and the Youth Innovation Promotion Association CAS (2017255, 2015169).

\section{Appendix A. Supplementary data}

Supplementary material related to this article can be found, in the online version, at doi:https://doi.org/10.1016/j.jhazmat.2019.120778.

\section{References}

[1] A. Filipkowska, L. Lubecki, M. Szymczak-Zyla, T.M. Ciesielski, B.M. Jenssen, M.V. Ardelan, H. Mazur-Marzec, G.D. Breedveld, A.M.P. Oen, A. Zamojska, G. Kowalewska, Anthropogenic impact on marine ecosystem health: a comparative multi-proxy investigation of recent sediments in coastal waters, Mar. Pollut. Bull. 133 (2018) 328-335, https://doi.org/10.1016/j.marpolbul.2018.05.058.

[2] A. Kunhikrishnan, H.K. Shon, N.S. Bolan, I. El Saliby, S. Vigneswaran, Sources, distribution, environmental fate, and ecological effects of nanomaterials in wastewater streams, critical reviews in wastewater streams, Environ. Sci. Technol. 45 (2015) 277-318, https://doi.org/10.1080/10643389.2013.852407.

[3] X.G. Hu, K.C. Lu, L. Mu, J. Kang, Q.X. Zhou, Interactions between graphene oxide and plant cells: regulation of cell morphology, uptake, organelle damage, oxidative effects and metabolic disorders, Carbon 80 (2014) 665-676, https://doi.org/10. 1016/j.carbon.2014.09.010.

[4] Q. Zhou, X. Hu, Systemic stress and recovery patterns of rice roots in response to graphene oxide nanosheets, Environ. Sci. Technol. 51 (2017), https://doi.org/10. 1021/acs.est.6b05591.

[5] C. Hu, N. Hu, X. Li, Y. Zhao, Graphene oxide alleviates the ecotoxicity of copper on the freshwater microalga Scenedesmus obliquus, Ecotoxicol. Environ. Saf. 132 (2016) 360-365, https://doi.org/10.1016/j.ecoenv.2016.06.029.

[6] Y. Wang, M. Tang, Review of in vitro toxicological research of quantum dot and potentially involved mechanisms, Sci. Total Environ. 625 (2018) 940-962, https:// doi.org/10.1016/j.scitotenv.2017.12.334.

[7] L. Pagano, A.D. Servin, R. De La Torre-Roche, A. Mukherjee, S. Majumdar, J. Hawthorne, M. Marmiroli, E. Maestri, R.E. Marra, S.M. Isch, O.P. Dhankher, J.C. White, N. Marmiroli, Molecular response of crop plants to engineered nanomaterials, Environ. Sci. Technol. 50 (2016) 7198-7207, https://doi.org/10.1021/ acs.est.6b01816.

[8] S.H. Ouyang, X.G. Hu, Q.X. Zhou, Envelopment-Internalization synergistic effects and metabolic mechanisms of graphene oxide on single-cell Chlorella vulgaris are dependent on the nanomaterial particle size, ACS Appl. Mater. Interfaces 7 (2015) 18104-18112, https://doi.org/10.1021/acsami.5b05328.

[9] A. Katsumiti, R. Tomovska, M.P. Cajaraville, Intracellular localization and toxicity of graphene oxide and reduced graphene oxide nanoplatelets to mussel hemocytes in vitro, Aquat. Toxicol. 188 (2017) 138-147, https://doi.org/10.1016/j.aquatox. 2017.04.016.

[10] C. Pretti, M. Oliva, R.D. Pietro, G. Monni, G. Cevasco, F. Chiellini, C. Pomelli, C. Chiappe, Ecotoxicity of pristine graphene to marine organisms, Ecotoxicol. Environ. Saf. 101 (2014) 138-145, https://doi.org/10.1016/j.ecoenv.2013.11.008.

[11] X.L. Zhang, Q.X. Zhou, W. Zou, X.G. Hu, Molecular mechanisms of developmental toxicity induced by graphene oxide at predicted environmental concentrations, Environ. Sci. Technol. 51 (2017) 7861-7871, https://doi.org/10.1021/acs.est. 7b01922.

[12] Y.M. Chen, X.G. Hu, J. Sun, Q.X. Zhou, Specific nanotoxicity of graphene oxide during zebrafish embryogenesis, Nanotoxicology 10 (2016) 42-52, https://doi.org/ 10.3109/17435390.2015.1005032.

[13] Y. Tang, J. Tian, S. Li, C. Xue, Z. Xue, D. Yin, S. Yu, Combined effects of graphene oxide and Cd on the photosynthetic capacity and survival of Microcystis aeruginosa, Sci. Total Environ. 532 (2015) 154-161, https://doi.org/10.1016/j.scitotenv.2015. 05.081.

[14] X. Li, L. Mu, X. Hu, Integrating proteomics, metabolomics and typical analysis to investigate the uptake and oxidative stress of graphene oxide and polycyclic aromatic hydrocarbons, Environ. Sci. Nano 5 (2018) 115-129, https://doi.org/10. 1039/C7EN00803A.

[15] S. Liu, W. Jiang, B. Wu, J. Yu, H. Yu, X.X. Zhang, C. Torres-Duarte, G.N. Cherr, Low 
levels of graphene and graphene oxide inhibit cellular xenobiotic defense system mediated by efflux transporters, Nanotoxicology 10 (2016) 597-606, https://doi org/10.3109/17435390.2015.1104739.

[16] D.D. Cao, J.H. Guo, Y.W. Wang, Z.N. Li, K. Liang, M.B. Corcoran, S. Hosseini, S.M.C. Bonina, K.J. Rockne, N.C. Sturchio, J.P. Giesy, J.F. Liu, A. Li, G.B. Jiang, Organophosphate esters in sediment of the great lakes, Environ. Sci. Technol. 51 (2017) 1441-1449, https://doi.org/10.1021/acs.est.6b05484.

[17] J. Castro-Jimenez, N. Berrojalbiz, M. Pizarro, J. Dachs, Organophosphate ester (OPE) flame retardants and plasticizers in the open mediterranean and black sea atmosphere, Environ. Sci. Technol. 48 (2014) 3203-3209, https://doi.org/10. 1021/es405337g.

[18] M. Zhong, H. Wu, W. Mi, F. Li, C. Ji, R. Ebinghaus, J. Tang, Z. Xie, Occurrences and distribution characteristics of organophosphate ester flame retardants and plasticizers in the sediments of the Bohai and Yellow Seas, China, Sci. Total Environ. 615 (2018) 1305-1311, https://doi.org/10.1016/j.scitotenv.2017.09.272.

[19] G. Wang, Z. Du, H. Chen, Y. Su, S. Gao, L. Mao, Tissue-specific accumulation, depuration, and transformation of triphenyl phosphate (TPHP) in adult zebrafish (Danio rerio), Environ. Sci. Technol. 50 (2016) 13555-13564, https://doi.org/10. 1021/acs.est.6b04697.

[20] X. Liu, K. Ji, K. Choi, Endocrine disruption potentials of organophosphate flame retardants and related mechanisms in H295R and MVLN cell lines and in zebrafish, Aquat. Toxicol. 114 (2012) 173-181, https://doi.org/10.1016/j.aquatox.2012.02. 019.

[21] G. Su, D. Crump, R.J. Letcher, S.W. Kennedy, Rapid in vitro metabolism of the flame retardant triphenyl phosphate and effects on cytotoxicity and mRNA expression in chicken embryonic hepatocytes, Environ. Sci. Technol. 48 (2014) 13511-13519, https://doi.org/10.1021/es5039547.

[22] F. Li, J.W. Ding, H.F. Wu, X.J. Meng, J.M. Zhao, Interaction between graphene joint triphenyl phosphate (TPP) and the simulated phospholipid bilayer of electrochemical research, China Sci. Bull. 62 (2017) 4285-4293, https://doi.org/10.1360/ N972017-00556.

[23] C. Della Torre, T. Balbi, G. Grassi, G. Frenzilli, M. Bernardeschi, A. Smerilli, P. Guidi, L. Canesi, M. Nigro, F. Monaci, V. Scarcelli, L. Rocco, S. Focardi, M. Monopoli, I. Corsi, Titanium dioxide nanoparticles modulate the toxicological response to cadmium in the gills of Mytilus galloprovincialis, J. Hazard. Mater. 297 (2015) 92-100, https://doi.org/10.1016/j.jhazmat.2015.04.072.

[25] S.K. Singh, M.K. Singh, M.K. Nayak, S. Kumari, S. Shrivastava, J.J. Gracio, D. Dash, Thrombus inducing property of atomically thin graphene oxide sheets, ACS Nano 5 (2011) 4987-4996, https://doi.org/10.1021/nn201092p.

[26] Z.G. Qu, X.C. He, M. Lin, B.Y. Sha, X.H. Shi, T.J. Lu, F. Xu, Advances in the understanding of nanomaterial-biomembrane interactions and their mathematical and numerical modeling, Nanomedicine 8 (2013) 995-1011, https://doi.org/10.2217/ Nnm.13.81.

[27] V. Matozzo, M. Battistara, I. Marisa, V. Bertin, A. Orsetti, Assessing the effects of amoxicillin on antioxidant enzyme activities, lipid peroxidation and protein carbonyl content in the clam Ruditapes philippinarum and the Mussel Mytilus galloprovincialis, B. Environ. Contam. Tox. 97 (2016) 521-527, https://doi.org/10.1007/ s00128-016-1902-8.

[28] S. Mittal, V. Kumar, N. Dhiman, L.K.S. Chauhan, R. Pasricha, A.K. Pandey, Physicochemical properties based differential toxicity of graphene oxide/reduced graphene oxide in human lung cells mediated through oxidative stress, Sci. Rep. 6 (2016) 1-19, https://doi.org/10.1038/s41598-018-33153-z.

[29] S. Zhu, F. Luo, W.C. Chen, B. Zhu, G.X. Wang, Toxicity evaluation of graphene oxide on cysts and three larval stages of Artemia salina, Sci. Total Environ. 595 (2017) 101-109, https://doi.org/10.1016/j.scitotenv.2017.03.224.

[30] G.L. Chen, Y.X. Jin, Y. Wu, L. Liu, Z.W. Fu, Exposure of male mice to two kinds of organophosphate flame retardants (OPFRs) induced oxidative stress and endocrine disruption, Environ. Toxicol. Pharmacol. 40 (2015) 310-318, https://doi.org/10. 1016/j.etap.2015.06.021.

[31] L.L. Ou, B. Song, H.M. Liang, J. Liu, X.L. Feng, B. Deng, T. Sun, L.Q. Shao, Toxicity of graphene-family nanoparticles: a general review of the origins and mechanisms, Part. Fibre Toxicol. 13 (2016) 1-24, https://doi.org/10.1186/s12989-016-0168-y.

[32] M. Dziewiecka, J. Karpeta-Kaczmarek, M. Augustyniak, L. Majchrzycki, M.A. Augustyniak-Jablokow, Evaluation of in vivo graphene oxide toxicity for Acheta domesticus in relation to nanomaterial purity and time passed from the exposure, J. Hazard. Mater. 305 (2016) 30-40, https://doi.org/10.1016/j.jhazmat. 2015.11.021.

[33] L.T. Zhi, M. Qu, M.X. Ren, L. Zhao, Y.H. Li, D.Y. Wang, Graphene oxide induces canonical Wnt/beta-catenin signaling-dependent toxicity in Caenorhabditis elegans, Carbon 113 (2017) 122-131, https://doi.org/10.1016/j.carbon.2016.11.041.

[34] N. Issa, N. Guillaumot, E. Lauret, N. Matt, C. Schaeffer-Reiss, A. Van Dorsselaer, J.M. Reichhart, F. Veillard, The circulating protease persephone is an immune sensor for microbial proteolytic activities upstream of the Drosophila toll pathway, Mol. Cell 69 (2018) 539-550, https://doi.org/10.1016/j.molcel.2018.01.029.

[35] Y. Liu, X.N. Wang, J. Wang, Y.G. Nie, H. Du, H. Dai, J.J. Wang, M.D. Wang, S.P. Chen, T.K. Hei, Z.X. Deng, L.J. Wu, A. Xu, Graphene oxide attenuates the cytotoxicity and mutagenicity of PCB 52 via activation of genuine autophagy, Environ. Sci. Technol. 50 (2016) 3154-3164, https://doi.org/10.1021/acs.est. 5b03895.

[36] T. Finkel, Signal transduction by reactive oxygen species, J. Cell Biol. 194 (2011) 7-15, https://doi.org/10.1083/jcb.201102095.

[37] L. Canesi, G. Frenzilli, T. Balbi, M. Bernardeschi, C. Ciacci, S. Corsolini, C. Della Torre, R. Fabbri, C. Faleri, S. Focardi, P. Guidi, A. Kocan, Interactive effects of nTiO2 and 2,3,7,8-TCDD on the marine bivalve Mytilus galloprovincialis, Aquat. Toxicol. 153 (2014) 53-65, https://doi.org/10.1016/j.aquatox.2013.11.002.

[38] L. Molnar, G.M. Keseru, A neural network based virtual screening of cytochrome P450 3A4 inhibitors, Bioorg. Med. Chem. Lett. 12 (2002) 419-421, https://doi.org/ 10.1016/S0960-894x(01)00771-5.

[39] L. Li, X.J. Li, Y.M. Wu, L. Yang, W.W. Li, Q. Wang, Vitellogenin regulates antimicrobial responses in chinese mitten crab, Eriocheir sinensis, Fish Shellfish Immunol. 69 (2017) 6-14, https://doi.org/10.1016/j.fsi.2017.08.002.

[40] M. Agnese, M. Verderame, E. De Meo, M. Prisco, L. Rosati, E. Limatola, R. del Gaudio, S. Aceto, P. Andreuccetti, A network system for vitellogenin synthesis in the mussel Mytilus galloprovincialis (L.), J. Cell. Physiol. 228 (2013) 547-555, https:// doi.org/10.1002/jcp.24161.

[41] Y.Y. Zhang, Q. Wang, Y.L. Ji, Q. Zhang, H.F. Wu, J. Xie, J.M. Zhao, Identification and mRNA expression of two 17 beta-hydroxysteroid dehydrogenase genes in the marine mussel Mytilus galloprovincialis following exposure to endocrine disrupting chemicals, Environ. Toxicol. Pharmacol. 37 (2014) 1243-1255, https://doi.org/10. 1016/j.etap.2014.04.027.

[42] X. Liu, K. Ji, A. Jo, H.B. Moon, K. Choi, Effects of TDCPP or TPP on gene transcriptions and hormones of HPG axis, and their consequences on reproduction in adult zebrafish (Danio rerio), Aquat. Toxicol. 134 (2013) 104-111, https://doi.org/ 10.1016/j.aquatox.2013.03.013.

[43] G.M. Isales, R.A. Hipszer, T.D. Raftery, A. Chen, H.M. Stapleton, D.C. Volz, Triphenyl phosphate-induced developmental toxicity in zebrafish: potential role of the retinoic acid receptor, Aquat. Toxicol. 161 (2015) 221-230, https://doi.org/10. 1016/j.aquatox.2015.02.009.

[44] Q. Mu, G. Du, T. Chen, B. Zhang, B. Yan, Suppression of human bone morphogenetic protein signaling by carboxylated single-walled carbon nanotubes, ACS Nano 3 (2009) 1139-1144, https://doi.org/10.1021/nn900252j.

[45] X. Jia, M. Hofmann, V. Meunier, B.G. Sumpter, J. Campos-Delgado, J.M. RomoHerrera, H. Son, Y.P. Hsieh, A. Reina, J. Kong, M. Terrones, M.S. Dresselhaus, Controlled formation of sharp zigzag and armchair edges in graphitic nanoribbons, Science 323 (2009) 1701-1705, https://doi.org/10.1126/science.1166862.

[46] X. Tian, Z.X. Yang, G.X. Duan, A.Q. Wu, Z.L. Gu, L.L. Zhang, C.Y. Chen, Z.F. Chai, C.C. Ge, R.H. Zhou, Graphene oxide nanosheets retard cellular migration via disruption of actin cytoskeleton, Small 13 (2017) 1-10, https://doi.org/10.1002/Smll. 201602133.

[47] R. Anupama, S. Sajitha Lulu, A. Mukherjee, S. Babu, Cross-regulatory network in Pseudomonas aeruginosa biofilm genes and $\mathrm{TiO}_{2}$ anatase induced molecular perturbations in key proteins unraveled by a systems biology approach, Gene 647 (2018) 289-296, https://doi.org/10.1016/j.gene.2018.01.042.

[48] G. Ghartey-Kwansah, Z. Li, R. Feng, L. Wang, X. Zhou, F.Z. Chen, M.M. Xu, O. Jones, Y. Mu, S. Chen, J. Bryant, W.B. Isaacs, J. Ma, X. Xu, Comparative analysis of FKBP family protein: evaluation, structure, and function in mammals and Drosophila melanogaster, BMC Dev. Biol. 18 (2018) 7-18, https://doi.org/10.1186/s12861018-0167-3.

[49] E.P. Bernick, P.J. Zhang, S. Du, Knockdown and overexpression of Unc-45b result in defective myofibril organization in skeletal muscles of zebrafish embryos, BMC Cell Biol. 11 (2010) 70-82, https://doi.org/10.1186/1471-2121-11-70.

[50] S. Sisakhtnezhad, In silico analysis of single-cell RNA sequencing data from 3 and 7 days old mouse spermatogonial stem cells to identify their differentially expressed genes and transcriptional regulators, J. Cell. Biochem. 119 (2018) 7556-7569, https://doi.org/10.1002/jcb.27066.

[51] S.Y. Dong, Q. Lou, G.Q. Huang, J.J. Guo, X.H. Wang, T.L. Huang, Dispersive solidphase extraction based on MoS2/carbon dot composite combined with HPLC to determine brominated flame retardants in water, Anal. Bioanal. Chem. 410 (2018) 7337-7346, https://doi.org/10.1007/s00216-018-1342-x.

[52] C. Ji, H. Wu, L. Wei, J. Zhao, J. Yu, Proteomic and metabolomic analysis reveal gender-specific responses of mussel Mytilus galloprovincialis to 2, 2', 4, 4'-tetrabromodiphenyl ether (BDE 47), Aquat. Toxicol. 140 (2013) 449-457, https://doi. org/10.1016/j.aquatox.2013.07.009. 